cantly with the phosphate potential.

Even an account as selective and idiosyncratic as this cannot end without acknowledging the scientific and organisational contribution of $\mathrm{Dr} \mathbf{J}$. Hatefi (Scripps Clinic and Research Foundation, La Jolla) and the committee of the University of Tehran. I hope that the interaction and contacts with Iranian biochemists will help to overcome the isolation which distance can still impose on the physical periphery of scientific communities. This would at least partially repay our hosts for a unique meeting.

\section{Tropical forest genetics}

from Ken Eldridge

\begin{abstract}
"Variation, Breeding and Conservation of Tropical Forest Trees" was the title of the international symposium conducted jointly by the Linnean Society of London, the International Union of Forestry Research Organisations (IUFRO) and the Commonwealth Forestry Institute, Oxford, 17-19 April. The meeting continued in Nigeria and Ghana as a IUFRO field workshop until 2 May.
\end{abstract}

"A FORESTER is a man who cuts trees down, wishes he hadn't and then tries to put them back", suggested K. A. Longman, of the Institute of Terrestrial Ecology, Edinburgh. Much of the discussion at the symposium centred on the loss of irreplaceable genetic resources of tropical forest trees, denying future generations the opportunity to find new crop plants for wood, food, fibre and medicines.

The evergreen forests of the wet tropics comprise $20 \%$ of the area of the world's remaining forest and carry $50 \%$ of the wood, a major natural resource which should be renewable. In fact it is not being renewed and its use, as J. F. Hughes, of Oxford University, said, is "generally inefficient and often potentially disastrous".

Several speakers emphasised the numenous kinds of breeding system and patterns of genetic variability in tropical forest trees. Some of the Meliaceae grow as rare individuals a long way apant increasing the chance of selfing; Triplochiton scleroxylon grows in small but widely separated groups, favouring the inbreeding of relatives; and tropical pines are in nearly pure stands, favouring outcrossing. Pollination can be by a multitude of insects, birds, bats, small mammals, wind, or various combinations. While some rainforest trees flower and seed almost continuously, others seed heavily only at intervals of several years.
T. Hedegart reported the work of the Thai-Danish Teak Improvement Centre which has the most advanced study of the breeding system of a tropical forest tree. The small flowers (6-8 $\mathrm{mm}$ diameter) have a one-day cycle and are receptive for only a few hours about mid-day. Experiments with hand pollination showed a high degree $(96-100 \%)$ of self incompatibility. When insect visitors were caught and washed it was found that two species of bee cannied most teak pollen.

Generalisations are not appropriate for highly variable characteristics of breeding systems. For this reason K. S. Bawa, of the University of Massachusetts, Boston, drew attention to the folly of uncritically applying genetic information from the relatively wellknown northern conifers to planning the conservation of genetic resources and genetic improvement of tropical forest trees.

New means to overcome the physical difficulties of studying the flowering and genetics of large trees were reported. P. S. Ashton (University of Aberdeen) described a system of spars and rigging and bosun's chairs used in a joint project of the Universities of Aberdeen and Malaya to study pollination in the canopy of a rainforest. Other speakers meported less gymnastic methods in forest genetics. A. N. Start and A. G. Marshall, of the University of Aberdeen, examined pollen in excreta of bats at their roosts to see which trees species they visited and how far they canried pollen. J. Burley, of Oxford University, used extensive progeny tests and analysed isozymes from endosperm and tenpenes from resin in seeking patterns of genetic variation in tropical pines.

The IUFRO workshop in Nigeria and Ghana "Variation and Breeding Systems of Triplochiton scleroxylon" presented the early results of concentrated research for the domestication of one tree. This fast-growing species is common in secondary forests in the humid tropics of West Africa. Although it is the major export timber of Nigeria it has been difficult to re-establish after cutting.

Recent field studies conducted by $\mathrm{N}$. Jones, of the Federal Depantment of Forest Research, Ibadan, have shown that irregular production of seed is largely due to variation in the abundance of a weevil and a smut fungus which destroy the developing seeds. Control of these parasites by collecting the fruit when it is still green can provide enough seed for a regular plantation programme.

N. Howland, also of FDFR, Ibadan, reported the development of a second means of establishing Triplochiton plantations by mass production of rooted cuttings from seedlings.
The meeting at Oxford and in West Africa brought out the need for a series of representative reserves to try to maintain a large part of the genetic variation in each of several tropical species. In heavily populated areas it is hard to keep reserves of natural forest which seem to be unused. Farmers demand to clear them for food crops. Even foresters are increasingly obliged to clear them for plantations of exotic trees. The contention that fast-growing plantations will take the pressure off the natural forests was disputed by $\mathrm{L}$. Roche, of the University of Ibadan, and other speakers who gave examples of plantations replacing natural forests, not saving them.

What is to be done? The obvious answer is a strong and comprehensive policy of land use, a political not a biological solution. The scientist's special contribution is to provide governments with biological evidence to support rational political and administrative action.

\section{Fe-S clusters in chemistry and biology}

from D. O. Hall

THE chemistry of the Fe-S clusters which form the active centres of ferredoxins is a blossoming field. Impetus has come in particular from Holm's group at the Massachusetts Institute of Technology who have synthesised analogues of the two types of cluster which are found in ferredoxins and have recently been able to wrap nineand twelve-chain peptides around the synthetic compounds (Endeavour, 34, $38 ; 1975)$. This and other work is shedding new light on the properties of $\mathrm{Fe}-\mathrm{S}$ centres.

The iron-sulphur proteins, of which the ferredoxins are an important group, are found in all species and catalyse a wide variety of metabolic reactions. They have the important ability to transfer electrons at very low potentials: between -600 and $-400 \mathrm{mV}$. They can form redox chains with haem and flavin proteins and can also form complexes with flavin and molybdenum in a single molecule.

These proteins contain equivalent amounts of sulphur and non-haem iron (attached to cysteine) in their active centres. The two types of cluster found in ferredoxins contain respectively $4 \mathrm{Fe}-4 \mathrm{~S}$ and $2 \mathrm{Fe}-2 \mathrm{~S}$ (see figure). Until about five years ago their lability made them difficult to study; the situation changed with the advent of techniques such as electron paramagnetic resonance and Mössbauer spectroscopy.

X-ray crystallography of proteins containing two 4Fe-4S-type clusters (one a ferredoxin containing $8 \mathrm{Fe}$ in 